\title{
Perbedaan Kemampuan Guru Menggunakan TIK Untuk Pengembangan Anak Usia Dini
}

\author{
Febrialismanto ${ }^{1 凶}$ \\ Pendidikan Guru Pendidikan Anak Usia Dini, Universitas Riau \\ DOI: $\underline{10.31004 / \text { obsesi.v5i2.743 }}$
}

\begin{abstract}
Abstrak
Pada umumnya guru anak usia dini belum memanfaatkan TIK untuk pengembangan anak usia dini. Tujuan penelitian ini untuk mengetahui perbedaan guru menggunakan atau memiliki TIK dengan yang tidak menggunakan atau memiliki TIK untuk pengembangan anak usia dini. Penelitian ini menggunakan metode komparatif dengan analisis Anova. Hasil penelitian menunjukkan bahwa guru yang menggunakan multimedia memiliki berbedaan pada pemanfaatan TIK untuk pengembangan anak usia dini, dukungan wifi di sekolah untuk guru memiliki berbedaan pada pemanfaatan TIK untuk pengembangan anak usia dini, guru yang menggunakan search engine memiliki berbedaan pemanfaatan TIK untuk pengembangan anak usia dini. Guru yang memiliki android tidak menunjukkan perbedaan pada pemanfaatan TIK untuk pengembangan anak usia dini, dan guru yang memiliki sosial media tidak menunjukkan perbedaan pada pemanfaatan TIK untuk pengembangan anak usia dini. Hasil penelitian ini memberikan informasi penggunaan TIK oleh guru untuk pembelajaran yang digunakan pada anak usia dini.
\end{abstract}

Kata Kunci: tik; perkembangan; guru paud

\begin{abstract}
In general, early childhood teachers have not used ICT for early childhood development. The purpose of this study was to determine the differences between teachers using or owning ICT with those who do not use or have ICT for early childhood development. This study uses a comparative method with ANOVA analysis. The results show that teachers who use multimedia have different uses of ICT for early childhood development, wifi support in schools for teachers has differences in the use of ICT for early childhood development, teachers who use search engines have different uses of ICT for early childhood development. Teachers who have androids do not show any difference in the use of ICT for early childhood development, and teachers who have social media do not show any differences in the use of ICT for early childhood development. The results of this study provide information on the use of ICT by teachers for learning used in early childhood.
\end{abstract}

Keywords: ict; development, early childhood teachers

Copyright (c) 2020 Febrialismanto

$\triangle$ Corresponding author :

Email Address : febrialismanto@lecturer.unri.ad.id (Pekanbaru, Indonesia)

Received 1 September 2020; Accepted 13 December 2020; Published 17 December 2020 


\section{PENDAHULUAN}

Penguasaan teknologi dalam pembelajaran sudah menjadi keharusan bagi seorang guru. Guru saat ini harus dapat menguasai teknologi agar dapat digunakan sebagai alat informasi ataupun komunikasi. Kemampuan penggunaan teknologi informasi dan komunikasi menjadi nilai tambah guru terutama untuk mendapatkan informasi yang lebih cepat dan valid. Kemampuan mendapatkan dan memberikan informasi merupakan salah satu modal guru untuk melakukan pembelajaran. Dalam proses pembelajaran keterharuan pengetahuan yang diberikan kepada peserta didik sangat diperlukan hal ini dikarenakan supaya anak didik mendapatkan pengetahuan yang baru. Pengetahuan terbaru yang didapatkan oleh peserta didik berguna untuk mempersiapkan diri untuk menghadapi tantangan pada masa yang akan datang. Memperkenalkan teknologi kepada peserta didik diperlukan kemahiran atau keahlian guru. Guru yang memiliki kemampuan yang baik dalam bidang teknologi lebih terbantu dalam proses pembelajaran dengan menggunakan teknologi jika dibandingkan guru yang belum mahir atau sama sekali belum dapat menguasai teknologi dalam pembelajaran. Mempersiapkan diri merupakan modal dasar guru dalam menghadapi tantangan pembelajaran dalam bidang teknologi.

Pembelajaran di Taman Kanak-kanak ada beberapa aspek perkembangan yang harus mendapatkan perhatian guru Indonesia, (2014) yaitu nilai agama dan moral, fisik motorik, kognitif, bahasa, sosial emosional, dan seni. Pada saat ini pengembangan banyak dilakukan dengan menggunakan cara yang konvensional. Penggunaan TIK dalam pembelajaran pengembangan masih jarang digunakan. Rusi Restiyani, Nengsi Juanengsih, (2013) menjelaskan bahwa kemampuan literasi guru yang berupa kemampuan membaca, berbicara, melihat, mendengarkan dan berpendapat yang baik berpotensi pada kemampuan pemanfaatan TIK. Artinya guru yang meningkatkan kualitas dirinya memberikan dampak yang baik terhadap pemanfaatan terhadap TIK. Pemanfaatan TIK dalam pembelajaran merupakan tantangan bagi guru masa depan. Nisa, (2020) Teknologi berperan dalam proses kegiatan pembelajaran dan meningkatkan kualitas pendidikan. Tidak semua pendidik yang dapat memanfaatkan teknologi untuk media pembelajaran. Pemberian pelatihan dan pendampingan diperlukan agar pendidik dapat meningkatkan kemampuan penguasaan teknologi untuk pembelajaran. (Sum, 2019) guru menggunakan teknologi informasi dan komunikasi untuk kegiatan pembelajaran masih dalam kategori cukup.

Febrialismanto \& Nur, (2019) menjelaskan bahwa secara umum guru masih belum banyak menggunakan TIK untuk pembelajaran di PAUD. Hal ini dapat dilihat pada, menggunakan TIK membuat bahan pembelajaran pengembangan, menggunakan TIK mengubah pembelajaran pengembangan, menggunakan TIK menyimpan bahan dan hasil pembelajaran pengembangan, menggunakan TIK mengkomunikasikan bahan dan hasi pembelajaran pengembangan, dan Menggunakan TIK untuk menyebarkan informasi bahan dan hasil pembelajaran pengembangan. Dari penjelasan tersebut dapat diketahui bahwa guru PAUD pada umumnya belum menggunakan TIK untuk pembelajaran pengembangan untuk anak usia dini. Pengenalan dan penggunaan teknologi perlu dilakukan pada proses pembelajaran. Ini dikarenakan untuk mempersiapkan anak dari dini dapat mengenali dan bisa menggunakan teknologi yang umum digunakan dalam kehidupan sehari-hari. Febrialismanto \& Nur, (2020) menjelaskan bahwa guru telah menggunakan multimedia, memiliki, android, memiliki sosial media tetapi belum digunakan untuk pembelajaran pengembangan anak. Fasilitas pendukung dari sekolah seperti Wifi juga masih belum digunakan untuk pembelajaran pengembangan anak. Hanya guru yang menggunakan mesin pencari atau search engine yang menunjukkan hubungan dengan penggunaan pembelajaran pengembangan dengan menggunakan TIK di PAUD. Dari penjelasan tersebut dapat diketahui aktivitas penggunaan teknologi yang digunakan guru masih belum menunjukkan hubungan dengan kegiatan pembelajaran yang dilakukan oleh guru terutama guru menggunakan TIK pada proses pembelajaran di PAUD. 
Berdasarkan dari artikel sebelumnya dapat diketahui gambaran pemanfaatan TIK dalam pembelajaran masih rendah dan hubungan aktivitas penggunaan TIK untuk pembelajaran pengembangan di AUD belum menunjukkan hubungan yang signifikan. Kemudian yang belum terungkap adalah perbedaan guru yang melakukan atau memiliki TIK dengan guru yang tidak melakukan atau memiliki TIK. Pengungkapan ini perlu dilakukan untuk melihat perbedaan guru yang memiliki atau memanfaatkan teknologi dengan guru yang belum memiliki atau manfaatkan teknologi dalam pembelajaran pengembangan untuk AUD.

\section{METODOLOGI}

Metode yang digunakan dalam penelitian ini adalah metode komparatif dengan menggunakan analisis Anova. Penelitian ini melihat perbedaan antara guru yang memanfaatkan TIK dengan Guru yang tidak Memanfaatkan TIK. Sampel penelitian menggunakan metode sampling insidental yakni teknik pengambilan sampel berdasarkan kebetulan bertemu atau berpartisipasi dalam penelitian. Sampel merupakan orang yang dipandang cocok sebagai sumber data. Sampel penelitian ini adalah guru yang berada di Provinsi Riau yang berpartisipasi mengisi angket online. Guru yang berpartisipasi sebanyak 67 orang.

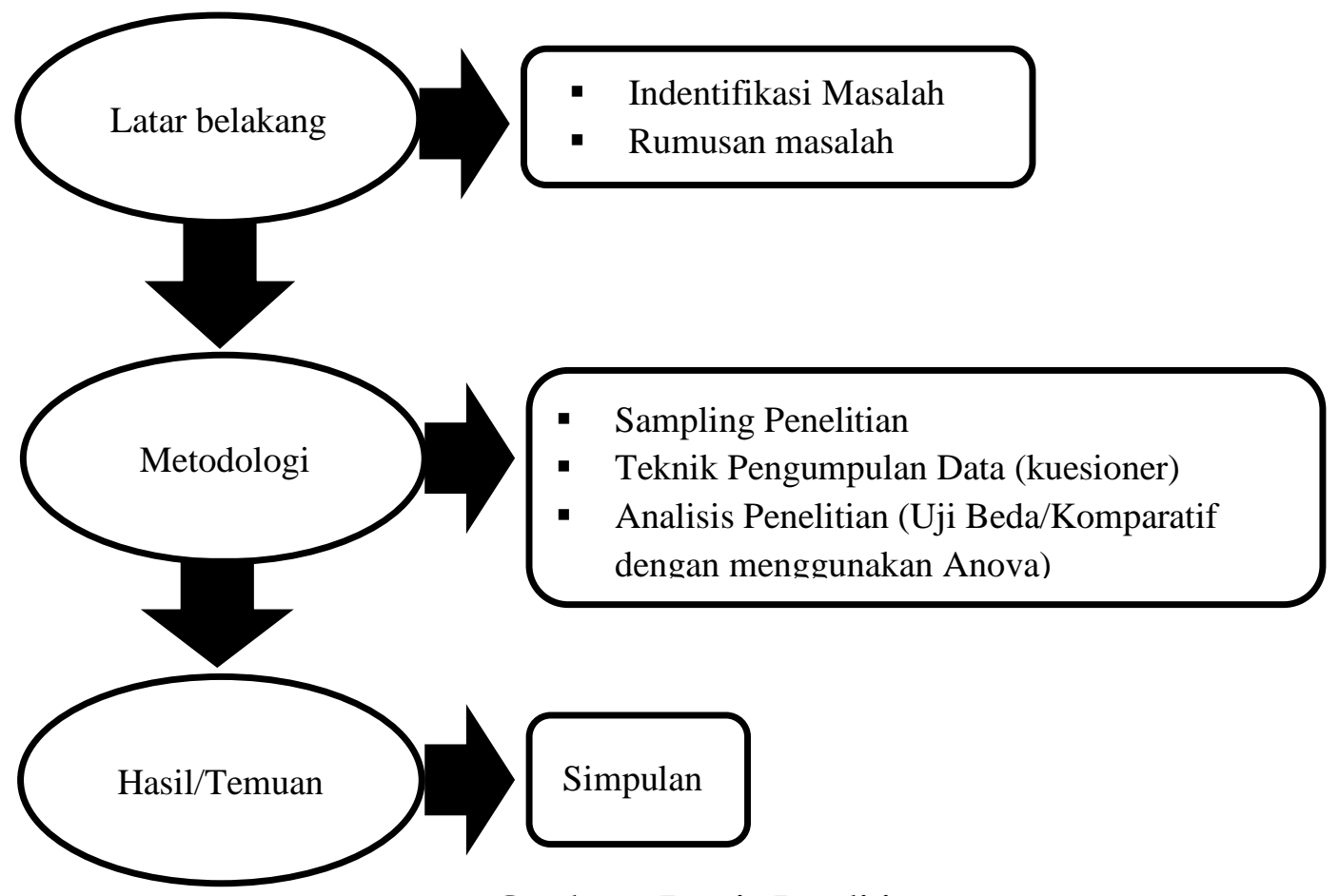

Gambar 1. Desain Penelitian

\section{HASIL DAN PEMBAHASAN}

Untuk menentukan kriteria hasil perhitungan deskriptif menggunakan pedoman pengukuran pada tabel 1 .

Tabel 1. kriteria hasil perhitungan deskriptif

\begin{tabular}{|l|l|l|}
\hline & & \\
\hline a & $>80 \%$ & Tinggi \\
\hline b & $>60 \%-<80 \%$ & Cukup Tinggi \\
\hline c & $>40 \%-<60 \%$ & Rendah \\
\hline d & $<40 \%$ & Sangat Rendah \\
\hline
\end{tabular}

(Febrialismanto \& Hukmi, 2018): 
Perbedaan Guru Memanfaatkan Multimedia menggunakan TIK Untuk Pembelajaran Pengembangan

Tabel 2 output SPSS perbedaan rata-rata guru menggunakan Multimedia dari 2 kelompok

\begin{tabular}{|c|c|c|c|c|c|c|c|c|}
\hline \multicolumn{9}{|c|}{ Descriptives } \\
\hline & \multirow[b]{2}{*}{$\mathrm{N}$} & \multirow[b]{2}{*}{ Mean } & \multirow[b]{2}{*}{$\begin{array}{c}\text { Std. } \\
\text { Deviation }\end{array}$} & \multirow[b]{2}{*}{$\begin{array}{l}\text { Std. } \\
\text { Error }\end{array}$} & \multicolumn{2}{|c|}{$\begin{array}{l}95 \% \text { Confidence Interval } \\
\text { for Mean }\end{array}$} & \multirow[b]{2}{*}{ Minimum } & \multirow[b]{2}{*}{ Maximum } \\
\hline & & & & & $\begin{array}{l}\text { Lower } \\
\text { Bound }\end{array}$ & $\begin{array}{l}\text { Upper } \\
\text { Bound }\end{array}$ & & \\
\hline $\mathrm{Ya}$ & 49 & 82.2245 & 20.46874 & 2.92411 & 76.3452 & 88.1038 & 41.00 & 139.00 \\
\hline Tidak & 18 & 70.6667 & 17.28651 & 4.07447 & 62.0703 & 79.2630 & 41.00 & 103.00 \\
\hline Total & 67 & 79.1194 & 20.20690 & 2.46867 & 74.1906 & 84.0483 & 41.00 & 139.00 \\
\hline
\end{tabular}

Berdasarkan output SPSS dapat diketahui perbedaan rata-rata guru menggunakan Multimedia dari 2 kelompok dapat diketahui bahwa guru yang menggunakan multimedia rata-rata menggunakan TIK untuk pembelajaran pengembangan $(82.22 / 140)^{*} 100=59 \%$ Kategori cukup tinggi. Dari tabel deskriptif dapat diketahui bahwa guru yang tidak menggunakan multimedia rata-rata menggunakan TIK untuk pembelajaran pengembangan $(70.67 / 140)^{*} 100=50 \%$ Katergori rendah

Tabel 3. Test of Homogeneity of Variances

\begin{tabular}{rrrrr}
\hline $\begin{array}{l}\text { Levene } \\
\text { Statistic }\end{array}$ & df1 & & df2 & \multicolumn{1}{c}{ Sig. } \\
\hline .939 & & 1 & 65 & .336 \\
\hline
\end{tabular}

Berdasarkan output SPSS pada tabel 3, dapat diketahui angka Levene Statistik sebesar 0.939 dengan signifikansi atau probabilitas (sig) sebesar 0.336. Nilai signifikansi 0.336 lebih besar dari 0.050 dapat disimpulkan bahwa kelompok umur tersebut adalah homogen.

Tabel 4. Anova

\begin{tabular}{lcrrrr}
\hline & $\begin{array}{l}\text { Sum of } \\
\text { Squares }\end{array}$ & df & Mean Square & F & Sig. \\
\hline Between Groups & 1758.514 & 1 & 1758.514 & 4.538 & .037 \\
\hline Within Groups & 25190.531 & 65 & 387.547 & & \\
\hline Total & 26949.045 & 66 & & & \\
\hline
\end{tabular}

Dasar untuk menentukan analisis Anova yaitu; Jika signifikansi (Sig) $>0.05$ maka ratarata sama dan jika signifikansi (Sig) $<0.05$ maka rata-rata tidak sama.

Berdasarkan output Anova pada tabel 4, dapat diketahui bahwa nilai signifikansi (sig) $0.037<0.05$ sehingga dapat disimpulkan bahwa data berbeda secara signifikan menggunakan multimedia dalam pembelajaran. Artinya ada perbedaan penggunaan TIK dalam pembelajaran perkembangan antara guru yang menggunakan multimedia dengan guru yang tidak menggunakan multimedia.

Dari hasil penelitian dapat diketahui bahwa terdapat perbedaan antara guru memanfaatkan multimedia menggunakan TIK dengan guru yang tidak menggunakan multimedia menggunakan TIK. Guru yang telah memanfaatkan multimedia dalam proses pembelajaran dengan menggunakan TIK memiliki cara yang berbeda memanfaatkan TIK untuk Pembelajaran Pengembangan dibandingkan dengan guru yang tidak menggunakan multimedia. Priyanto, (2009) menjelaskan penggunaan multimedia dalam pembelajaran memiliki urgensi yang besar. Multimedia berbasis komputer memiliki perbedaan lebih dibandingkan dengan menggunakan media yang lain. Pengembangan media dengan 
menggunakan komputer diperlukan untuk meningkatkan kualitas pembelajaran sehingga dapat dicapai pembelajaran active learning yang menekankan keaktifan siswa dalam proses pembelajaran. Dengan demikian diharapkan tujuan pembelajaran dapat dicapai dengan baik. Ramdan, Hamidah, \& Purnawan, (2015) pemanfaatan multimedia dalam proses pembelajaran memberikan dampak pada peningkatan hasil yang didapatkan oleh peserta didik.

Diah \& Nita, (2018) penggunaan media pembelajaran dengan menggunakan multimedia layak digunakan dalam proses pembelajaran. Shilpa \& Sunita, (2013) menjelaskan bahwa perangkat multimedia memiliki kualitas untuk meningkatkan pendidikan. anak usia dini. Media visual dapat digunakan untuk meningkatkan nilai-nilai moral pada anak usia dini. Media visual ini memberikan pengetahuan interaktif karena anak merasa dalam situasi yang nyata. Zulhelmi, Adlim, \& Mahidin, (2017) Penggunaan multimedia dalam proses pembelajaran dapat meningkatkan kompetensi peserta didik. (Nopriyanti \& Sudira, (2015) software multimedia pembelajaran interaktif layak untuk digunakan dalam proses pembelajaran. Penggunaan dengan memperhatikan kualitas software multimedia tersebut. Hendriawan \& Muhammad, (2018) penggunaan multimedia berbasis android dapat digunakan dalam proses pembelajaran. Pemanfaatan multimedia berbasis android dapat digunakan sebagai penunjang belajar peserta didik. Meolbatak \& Bria, (2016) menjelaskan penggunaan multimedia dapat digunakan sebagai model pembelajaran salah satunya adalah dengan model inquiri. Model ini menuntut peserta didik untuk aktif dalam proses pembelajaran. Peserta didik yang aktif dalam proses pembelajaran lebih kreatif dan dapat memecahkan permasalahan yang ditemukannya.

\section{Perbedaan Guru Sekolah Yang Memiliki WIFI menggunakan TIK Untuk Pembelajaran Pengembangan}

Tabel 5. Descriptives

\begin{tabular}{|c|c|c|c|c|c|c|c|c|}
\hline & \multirow[b]{2}{*}{$\mathrm{N}$} & \multirow[b]{2}{*}{ Mean } & \multirow[b]{2}{*}{$\begin{array}{c}\text { Std. } \\
\text { Deviation }\end{array}$} & \multirow[b]{2}{*}{$\begin{array}{l}\text { Std. } \\
\text { Error }\end{array}$} & \multicolumn{2}{|c|}{$\begin{array}{l}95 \% \text { Confidence Interval } \\
\text { for Mean }\end{array}$} & \multirow[b]{2}{*}{ Minimum } & \multirow[b]{2}{*}{ Maximum } \\
\hline & & & & & $\begin{array}{l}\text { Lower } \\
\text { Bound }\end{array}$ & $\begin{array}{l}\text { Upper } \\
\text { Bound }\end{array}$ & & \\
\hline $\mathrm{Ya}$ & 16 & 89.3125 & 23.19689 & 5.79922 & 76.9517 & 101.6733 & 56.00 & 137.00 \\
\hline Tidak & 51 & 75.9216 & 18.27221 & 2.55862 & 70.7824 & 81.0607 & 41.00 & 139.00 \\
\hline Total & 67 & 79.1194 & 20.20690 & 2.46867 & 74.1906 & 84.0483 & 41.00 & 139.00 \\
\hline
\end{tabular}

Berdasarkan output SPSS pada tabel 5, dapat diketahui perbedaan rata-rata guru menggunakan wifi dari 2 kelompok yaitu; sekolah yang memiliki wifi rata-rata menggunakan TIK untuk pembelajaran pengembangan $(89.22 / 140)^{*} 100=50 \%$ Katergori rendah dan sekolah tidak memiliki wifi rata-rata menggunakan TIK untuk pembelajaran pengembangan $(75.92 / 140)^{*} 100=\mathbf{5 4} \%$ Rendah.

Tabel 6. Test of Homogeneity of Variances

\begin{tabular}{crrrr}
\hline $\begin{array}{l}\text { Levene } \\
\text { Statistic }\end{array}$ & df1 & & df2 & Sig. \\
\hline 2.136 & & 1 & 65 & .149 \\
\hline
\end{tabular}

Berdasarkan output SPSS pata tabel 6 dapat diketahui angka Levene Statistik sebesar 2.136 dengan signifikansi atau probabilitas (sig) sebesar 0.149. Nilai signifikansi 0.149 lebih besar dari 0.050 dapat disimpulkan bahwa kelompok umur tersebut adalah homogen.

Tabel 7. Abalisis Anova 


\begin{tabular}{lcrrrrr}
\hline & $\begin{array}{l}\text { Sum of } \\
\text { Squares }\end{array}$ & df & & Mean Square & F & \multicolumn{1}{c}{ Sig. } \\
\hline Between Groups & 2183.921 & 1 & 2183.921 & 5.732 & .020 \\
\hline Within Groups & 24765.124 & 65 & 381.002 & & \\
\hline Total & 26949.045 & 66 & & & \\
\hline
\end{tabular}

Dasar untuk menentukan analisis Anova adalah jika signifikansi (Sig) $>0.05$ maka ratarata sama dan jika signifikansi (Sig) $<0.05$ maka rata-rata tidak sama

Berdasarkan output Anova pada tabel 7 dapat diketahui bahwa nilai signifikansi (sig) $0.020<0.05$ sehingga dapat disimpulkan bahwa data berbeda secara signifikan memiliki wifi dengan menggunakan TIK dalam pembelajaran pengembangan. Artinya ada perbedaan penggunaan TIK dalam pembelajaran perkembangan antara guru yang sekolahnya memiliki wifi dengan guru yang sekolahnya tidak memiliki wifi.

Jelita, (2013) penggunaan Wifi pada proses pembelajaran memberikan dampak terhadap hasil belajar peserta didik. Alwraikat, (2015) penggunaan akses inernet nirkabel dibutuhkan oleh peserta didik dalam pembelajaran. Pentingnya menyediakan layanan untuk memfasilitasi perangkat nirkabel dalam proses pembelajaran untuk mengikuti perkembangan teknologi. Priantama, (2017) penyediaan sarana dan prasarana penggunaan internet dalam proses pembelajaran memberikan manfaat terhadap lingkungan belajar peserta didik. Suharmanto \& Sunarso, (2017) kendala dalam pembelajaran TIK salah diantaranya Wifi sekolah dan jaringan internet sekolah. Keberadaan Wifi untuk pembelajaran TIK sangat diperlukan. Pada saat ini sekolah yang maju sudah didukung adanya Wifi di sekolah. Setiyani, (2010) memperbanyak area hotspot membantu kecepatan mengakses internet sehingga informasi dapat didapat lebih cepat dan lebih banyak. Informasi ini dapat dimanfaatkan oleh kepala sekolah, guru, dan anak didik. Kemampuan guru untuk menggunakan TIK sangat diperlukan Husain, (2014) menjelaskan penggunaan TIK dalam proses pembelajaran belum digunakan dengan maksimal. Dibutuhkan keprofesionalan guru untuk menggunakan TIK dalam proses pembelajaran sedangkan saat ini keprofesionalan guru merupakan masalah besar yang dihadapi dalam pembelajaran TIK. Pemberian motivasi dari pihak atasan diperlukan kepada guru dan juga memberikan fasilitas dan pelatihan. Agar keberadaan Wifi dapat dimanfaatkan dengan baik guru harus memiliki kemampuan untuk menggunakan TIK pembelajaran.

Perbedaan Guru Memiliki Android menggunakan TIK Untuk Pembelajaran Pengembangan

Tabel 8. Descriptives

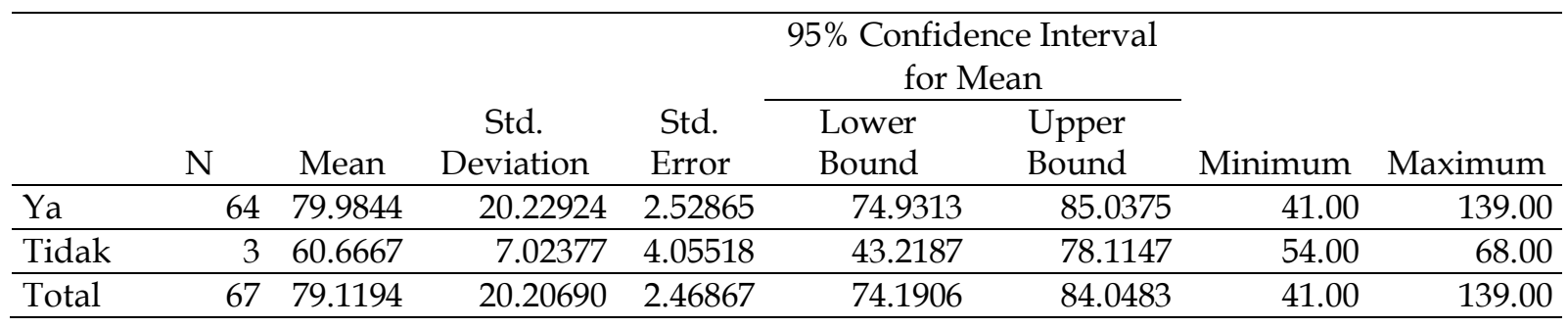

Berdasarkan output SPSS tabel 8, dapat diketahui perbedaan rata-rata guru menggunakan Android dari 2 kelompok dapat diketahui bahwa guru yang menggunakan memiliki android rata-rata menggunakan TIK untuk pembelajaran pengembangan $(79.98 / 140)^{*} 100=57 \%$ Rendah dan guru yang tidak menggunakan multimedia rata-rata menggunakan TIK untuk pembelajaran pengembangan $(60.66 / 140) * 100=43 \%$ Rendah.

Tabel 9. Test of Homogeneity of Variances 
Perbedaan Kemampuan Guru Menggunakan TIK Untuk Pengembangan Anak Usia Dini

DOI: $10.31004 /$ obsesi.v5i2.743

\begin{tabular}{|c|c|c|c|}
\hline $\begin{array}{l}\text { Levene } \\
\text { Statistic }\end{array}$ & df1 & df2 & Sig. \\
\hline 2.143 & 1 & 65 & .148 \\
\hline
\end{tabular}

Berdasarkan output SPSS pada tabel 9, dapat diketahui angka Levene Statistik sebesar 2.143 dengan signifikansi atau probabilitas (sig) sebesar 0.148. Nilai signifikansi 0.148 lebih besar dari 0.050 dapat disimpulkan bahwa kelompok umur tersebut adalah homogen.

Tabel 10. Analisis Anova

\begin{tabular}{lcrrrr}
\hline & $\begin{array}{l}\text { Sum of } \\
\text { Squares }\end{array}$ & df & Mean Square & F & Sig. \\
\hline Between Groups & 1069.394 & 1 & 1069.394 & 2.686 & .106 \\
\hline Within Groups & 25879.651 & 65 & 398.148 & & \\
\hline Total & 26949.045 & 66 & & & \\
\hline
\end{tabular}

Dasar untuk menentukan analisis Anova yaitu; jika signifikansi (Sig) $>0.05$ maka ratarata sama dan jika signifikansi $(\mathrm{Sig})<0.05$ maka rata-rata tidak sama

Berdasarkan output Anova pada tabel 10, dapat diketahui bahwa nilai signifikansi (sig) $0.106>0.05$ sehingga dapat disimpulkan bahwa data tidak berbeda secara signifikan memiliki Android menggunakan TIK dalam pembelajaran pengembangan. Artinya tidak ada perbedaan penggunaan TIK dalam pembelajaran perkembangan antara guru yang memiliki android dengan guru yang tidak memiliki android.

Dari hasil penelitian dapat diketahui bahwa guru yang memiliki android dengan yang tidak memiliki android tidak memiliki perbedaan menggunakan TIK untuk pembelajaran pengembangan. Pada umumnya guru sudah memiliki android tetapi belum dimanfaatkan untuk pembelajaran. Android dapat digunakan untuk pembelajaran penjelasan Hendikawati, Zahid, \& Arifudin, (2019) android dapat dijadikan sebagai media pembelajaran yang sebelumnya mendapatkan validasi dari para ahli. Anak dapat mengatur pembelajaran yang diikutinya dan lebih terdorong untuk dapat belajar mandiri. Wiwik \& Mulyani, (2018) penggunaan android dapat meningkatkan pembelajaran dan memberikan dampak yang positif pada pembelajaran. Alqahtani \& Mohammad, (2017) penggunaan teknologi dalam pembelajaran bukan merupakan sesuatu yang baru. Penggunaan android dalam pembelajaran pada saat ini sudah digunakan secara luas. Dengan mempelajari dampak dari penggunaan android memberikan pemahaman yang baik untuk penggunanya. Astra, Nasbey, \& Nugraha, (2015) penggunaan aplikasi pembelajaran dapat digunakan untuk proses pembelajaran untuk peserta didik. Smartphone sebagai salah satu alat pembelajaran dapat digunakan untuk proses pembelajaran. Purbosari, (2016) penggunaan smartphone dapat diaplikasikan di sekolah sebagai fasilitas pembelajaran. Penggunaan smartphone merupakan salah satu bentuk inovasi pembelajaran yang dapat membantu guru dan meningkatkan motivasi siswa dalam pembelajaran tersebut.

Martono \& Nurhayati, (2014) penggunaan mobile learning proses pembelajaran dapat dilakukan pada tempat yang tidak mengikat, dan memudahkan proses pembelajaran. Aripin, (2018) mobile learning merupakan cara untuk mempermudah proses pembelajaran dan dapat menggunakan beberapa model dalam pembelajaran. Komariah, Suhendri, \& Hakim, (2018) media pembelajaran yang dikembangkan dengan menggunakan android layak digunakan oleh peserta didik. Muyaroah \& Fajartia, (2017) menggunakan media pembelajaran berbasis android dapat meningkatkan hasil pembelajaran. Media pembelajaran tersebut dapat membuat peserta didik senang, tidak bosan dan takut. Setiadi, Yuliatmojo, \& Nurhidayat, (2018) pengembangan pembelajaran dengan menggunakan android meningkatkan hasil belajar peserta didik. Saefi, Lukiati, \& Suarsini, (2017) pembelajaran menggunakan android akan efektif dengan menggunakan satu android setiap peserta didik, pembelajaran fokus bada bahasan yang sedang dilakukan, proses pembelajaran dapat tercatat secara otomatis sehingga 
akan memudahkan guru untuk melakukan evaluasi. Irnin Agustina Dwi Astuti, Dasno, (2018) diperlukan memberi pelatihan kepada guru dapat meningkatkan antusias guru dan minat dengan menggunakan android untuk dijadikan media pembelajaran. Penunjang sarana dan prasarana diperlukan guru untuk meningkatkan kemampuan dalam menguasai android untuk pembelajaran.

\section{Perbedaan Guru Memiliki Sosial Media menggunakan TIK Untuk Pembelajaran Pengembangan}

Tabel 11. Descriptives

\begin{tabular}{|c|c|c|c|c|c|c|c|c|}
\hline & \multirow[b]{2}{*}{$\mathrm{N}$} & \multirow{2}{*}{ Mean } & \multirow[b]{2}{*}{$\begin{array}{c}\text { Std. } \\
\text { Deviation }\end{array}$} & \multirow[b]{2}{*}{$\begin{array}{l}\text { Std. } \\
\text { Error }\end{array}$} & \multicolumn{2}{|c|}{$\begin{array}{l}95 \% \text { Confidence Interval } \\
\text { for Mean }\end{array}$} & \multirow{2}{*}{ Minimum } & \multirow{2}{*}{ Maximum } \\
\hline & & & & & $\begin{array}{l}\text { Lower } \\
\text { Bound }\end{array}$ & $\begin{array}{l}\text { Upper } \\
\text { Bound }\end{array}$ & & \\
\hline$Y a$ & 65 & 79.0462 & 20.16063 & 2.50062 & 74.0506 & 84.0417 & 41.00 & 139.00 \\
\hline Tidak & 2 & 81.5000 & 30.40559 & 21.50000 & -191.6834 & 354.6834 & 60.00 & 103.00 \\
\hline Total & 67 & 79.1194 & 20.20690 & 2.46867 & 74.1906 & 84.0483 & 41.00 & 139.00 \\
\hline
\end{tabular}

Berdasarkan output SPSS dapat diketahui perbedaan rata-rata guru menggunakan Sosial Media dari 2 kelompok yaitu; guru yang memiliki sosial media rata-rata menggunakan TIK untuk pembelajaran pengembangan $(79.05 / 140)^{*} 100=56 \%$ Rendah dan guru yang tidak memiliki sosial media rata-rata menggunakan TIK untuk pembelajaran pengembangan $(81.50 / 140) * 100=58 \%$ Rendah.

Tabel 12. Test of Homogeneity of Variances

\begin{tabular}{rrrrr}
\hline $\begin{array}{l}\text { Levene } \\
\text { Statistic }\end{array}$ & df1 & & \multicolumn{1}{c}{ df2 } & \multicolumn{1}{c}{ Sig. } \\
\hline .446 & & 1 & 65 & .507 \\
\hline
\end{tabular}

Berdasarkan output SPSS dapat diketahui angka Levene Statistik sebesar 0.446 dengan signifikansi atau probabilitas (sig) sebesar 0.507. Nilai signifikansi 0.507 lebih besar dari 0.050 dapat disimpulkan bahwa kelompok umur tersebut adalah homogen.

Tabel 13. Analisis Anova

\begin{tabular}{|c|c|c|c|c|c|}
\hline & $\begin{array}{l}\text { Sum of } \\
\text { Squares }\end{array}$ & $\mathrm{df}$ & Mean Square & $\mathrm{F}$ & Sig. \\
\hline Between Groups & 11.683 & 1 & 11.683 & .028 & .867 \\
\hline Within Groups & 26937.362 & 65 & 414.421 & & \\
\hline Total & 26949.045 & 66 & & & \\
\hline
\end{tabular}

Dasar untuk menentukan analisis Anova yaitu ; jika signifikansi (Sig) $>0.05$ maka ratarata sama dan jika signifikansi (Sig) $<0.05$ maka rata-rata tidak sama.

Berdasarkan output Anova dapat diketahui bahwa nilai signifikansi (sig) $0.867>0.05$ sehingga dapat disimpulkan bahwa data tidak berbeda memiliki sosial media menggunakan TIK dalam pembelajaran pengembangan. Artinya tidak ada perbedaan penggunaan TIK dalam pembelajaran perkembangan antara guru yang memiliki sosial media dengan guru yang tidak memiliki sosial media.

Dari hasil penelitian dapat diketahui bahwa guru yang memiliki sosial media dengan yang tidak memiliki sosial media tidak memiliki perbedaan menggunakan TIK untuk pembelajaran pengembangan. A. S. Nurhayati, (2016) Media sosial memberikan perubahan yang radikal dalam bidang pendidikan, jejaring sosial dapat dijadikan media penunjang pembelajaran dengan memanfaatkan fasilitas yang disediakan oleh facebook tersebut. Media 
sosial juga dapat dijadikan pembelajaran jarak jauh dengan peserta didik. Aspari, (2016) Media sosial merupakan media online penggunanya dapat berpartisipasi, dan berbagi. Hampir semua kehidupan sekarang ini berkaitan dengan media sosial yang tidak memiliki batasan wilayah dan mempermudah hubungan antar satu orang dengan orang lainnya. Dalam pembelajaran penggunaan media sosial juga dapat dilaksanakan. Assidik, (2018) guru memiliki peran dalam menggunakan sosial media. Sosial media dapat dimanfaatkan dalam media pembelajaran agar peserta didik dapat memahami literasi digital memahami informasi sehari-hari dan memiliki pikiran kritis terhadap informasi yang didapatkan. Kamhar \& Lestari, (2019) pembaharuan media dalam pembelajaran penting untuk dilaksanakan hal ini dilakukan untuk menghilangkan kejenuhan peserta didik dalam belajar. Media yang digunakan dapat berupa media yang dekat dekan kehidupan peserta didik seperti media sosial. Pada umumnya peserta didik sudah mengakses media sosial dalam kehidupan seharihari. Dengan menggunakan media sosial dalam proses pembelajaran membantu peserta didik untuk dapat menggunakan media secara baik.

Fadli, (2013) proses pembelajaran dengan menggunakan media sosial dapat meningkatkan kompetensi peserta didik. Sasmito, (2015) media sosial dapat digunakan sebagai media alternatif dalam pembelajaran. Media sosial membantu interaksi guru dan peserta didik tanpa dibatasi oleh tempat dan waktu belajar. Media sosial dapat memberikan motivasi belajar kepada peserta didik. Munirah, (2018) menggunakan media pembelajaran yang inovatif dan variasi diperlukan dalam pembelajaran. Whatsapp sebagai media sosial dapat digunakan untuk pembelajaran online oleh guru. Tafonao, (2018) media pembelajaran tidak dapat dipisahkan dalam dunia pendidikan. Media merupakan cara atau alat yang digunakan untuk menyampaikan pesan kepada peserta didik agar dapat memahami pesan yang disampaikan oleh guru. Perkembangan teknologi dapat digunakan sebagai sarana dalam pendidikan termasuk media yang disediakan oleh teknologi tersebut.

Perbedaan Guru Menggunakan Search Engine menggunakan TIK Untuk Pembelajaran Pengembangan

Tabel 14. Descriptives

\begin{tabular}{|c|c|c|c|c|c|c|c|c|}
\hline & \multirow[b]{2}{*}{$\mathrm{N}$} & \multirow[b]{2}{*}{ Mean } & \multirow[b]{2}{*}{$\begin{array}{c}\text { Std. } \\
\text { Deviation }\end{array}$} & \multirow[b]{2}{*}{$\begin{array}{l}\text { Std. } \\
\text { Error }\end{array}$} & \multicolumn{2}{|c|}{$\begin{array}{l}\text { 95\% Confidence } \\
\text { Interval for Mean }\end{array}$} & \multirow[b]{2}{*}{ Minimum } & \multirow[b]{2}{*}{ Maximum } \\
\hline & & & & & $\begin{array}{l}\text { Lower } \\
\text { Bound }\end{array}$ & $\begin{array}{l}\text { Upper } \\
\text { Bound }\end{array}$ & & \\
\hline $\mathrm{Ya}$ & 36 & 86.0556 & 20.24697 & 3.37449 & 79.2050 & 92.9061 & 59.00 & 139.00 \\
\hline $\begin{array}{l}\text { Kadang- } \\
\text { kadang }\end{array}$ & 28 & 72.6071 & 17.37461 & 3.28349 & 65.8700 & 79.3443 & 41.00 & 105.00 \\
\hline Tidak & 3 & 56.6667 & 3.05505 & 1.76383 & 49.0775 & 64.2558 & 54.00 & 60.00 \\
\hline Total & 67 & 79.1194 & 20.20690 & 2.46867 & 74.1906 & 84.0483 & 41.00 & 139.00 \\
\hline
\end{tabular}

Berdasarkan output SPSS dapat diketahui perbedaan rata-rata guru menggunakan Multimedia dari 2 kelompok yaitu; rata-rata menggunakan Search Engine yang ya $(89.06 / 140)^{*} 100=64 \%$ Cukup Tinggi, rata-rata menggunakan Search Engine Kadang-kadang $(72.60 / 140)^{*} 100=52 \%$ Rendah, rata-rata menggunakan Search Engine yang tidak $(56.67 / 140)^{*} 100=40 \%$ Rendah

Tabel 16. Test of Homogeneity of Variances

\begin{tabular}{|c|c|c|c|}
\hline $\begin{array}{l}\text { Levene } \\
\text { Statistic }\end{array}$ & df1 & $\mathrm{df} 2$ & Sig. \\
\hline 2.383 & 2 & 64 & .100 \\
\hline
\end{tabular}


Berdasarkan output SPSS dapat diketahui angka Levene Statistik sebesar 2.2383 dengan signifikansi atau probabilitas (sig) sebesar 0.100. Nilai signifikansi 0.100 lebih besar dari 0.050 dapat disimpulkan bahwa kelompok umur tersebut adalah homogen.

Tabel 17. Analisi Anova

\begin{tabular}{lrrrrr}
\hline & $\begin{array}{l}\text { Sum of } \\
\text { Squares }\end{array}$ & df & Mean Square & F & \multicolumn{1}{c}{ Sig. } \\
\hline Between Groups & 4431.811 & 2 & 2215.905 & 6.298 & .003 \\
\hline Within Groups & 22517.234 & 64 & 351.832 & & \\
\hline Total & 26949.045 & 66 & & & \\
\hline
\end{tabular}

Dasar untuk menentukan analisis Anova yaitu; jika signifikansi (Sig) $>0.05$ maka ratarata sama dan jika signifikansi $(\mathrm{Sig})<0.05$ maka rata-rata tidak sama.

Berdasarkan output Anova pada tabel 17 dapat diketahui bahwa nilai signifikansi (sig) $0.003<0.05$ sehingga dapat disimpulkan bahwa data berbeda secara signifikan menggunakan Browser pada penggunaan TIK dalam pembelajaran pengembangan. Artinya ada perbedaan penggunaan TIK dalam pembelajaran perkembangan antara guru yang terbiasa menggunakan search engine dengan guru yang tidak terbiasa menggunakan search engine.

Dari hasil penelitian dapat diketahui bahwa terdapat perbedaan antara guru menggunakan search engine untuk pembelajaran TIK sesuai dengan pengembangan anak dengan guru yang tidak menggunakan search engine untuk pembelajaran TIK dengan pengembangan anak. N. Nurhayati, Suciati, \& Heriyanti, (2014) informasi yang tersedia secara online membantu untuk menambah pengetahuan. Informasi online bisa didapatkan lebih cepat dibandingkan informasi cetak. Informasi ini didukung dengan adanya search engine yang membantu untuk mendapatkan informasi secara online. Ningrum, Toenlioe, \& Abidin, (2019) adanya search engine mempermudah seseorang mendapatkan informasi. Mudahnya mendapatkan akses informasi memberikan dampak kepada motivasi seseorang untuk mengembangkan kemampuan yang dimilikinya. Andri, (2009) peningkatan search engine memberikan dampak pada peningkatan informasi. Faslah, (2016) memberikan pelatihan kepada siswa untuk menggunakan google search engine dapat membantu meningkatkan pengetahuan, pengalaman, dan informasi yang didapatkan oleh siswa.

Dari hasil penelitian dapat diketahui bahwa guru belum menggunakan TIK dalam pembelajaran secara optimal. Kondisi ini tampak dari berbeda atau belum guru dalam pemanfaatan TIK untuk pembelajaran. Pendampingan untuk guru diperlukan untuk mengetahui dan memahami TIK dapat dimanfaatkan dalam pembelajaran. Zakiya \& Nurhafizah, (2019) diklat diperlukan untuk guru guna mengembangkan kualitas diri pembaharuan pengetahuan pendidikan agar guru lebih profesional pada bidangnya.

\section{SIMPULAN}

Guru yang memanfaatkan multimedia pada sekolah yang memiliki Wifi, dan menggunakan search engine, memiliki perbedaan dibandingkan guru yang tidak memanfaatkan dan menggunakannya, dalam memanfaatkan TIK untuk pembelajaran pengembangan di PAUD. Sedangkan guru yang memiliki android, dan memiliki sosial media tidak memiliki perbedaan dibandingkan dengan guru yang tidak memiliki, dalam memanfaatkan TIK untuk pembelajaran pengembangan di PAUD. Perbedaan menunjukkan warna berbeda yang dilakukan oleh guru untuk proses peningkatan pengembangan pada anak. Perbedaan tersebut menunjukkan adanya upaya peningkatan kualitas dalam proses pembelajaran oleh guru yang menggunakan TIK dibanding dengan guru yang belum menggunakan TIK.

\section{UCAPAN TERIMA KASIH}


Penulis mengucapkan terimakasih kepada semua pihak yang telah membantu proses penelitian ini terutama guru Taman Kanak-kanak di Provinsi Riau yang telah berpartisipasi dalam penelitian ini. Terimakasih kami ucapkan kepada Prodi Pendidikan Guru Pendidikan Anak Usia Dini (PGPAUD) FKIP Universitas Riau yang telah membantu proses penelitian ini.

\section{DAFTAR PUSTAKA}

Alqahtani, M., \& Mohammad, H. (2017). Mobile Applications ' Impact on Student Performance and Satisfaction. The Turkish Online Journal of Educational Technology -, 14(4), 102-112.

Alwraikat, M. (2015). Wireless internet technology to support learning in the university of Jordan: Students voices. International Journal of Interactive Mobile Technologies, 9(3), 4-10. https://doi.org/10.3991/ijim.v9i3.4031

Aripin, I. (2018). Konsep Dan Aplikasi Mobile Learning Dalam Pembelajaran Biologi. Bio Educatio, 3(1), 1-9.

Aspari, A. (2016). Simposium Nasional Ilmu Pengetahuan dan Teknologi (SIMNASIPTEK). Media Sosial Sebagai Media Pembelajaran Bahasa Pada Masyarakat Modern, 10-17.

Assidik, G. K. (2018). Pemanfaatan Media Sosial Sebagai Alternatif Media Pembelajaran Berbasis Literasi Digital yang Interaktif dan Kekinian. Seminar Nasional SAGA Universitas Ahmad Dahlan,

242-246. http:// seminar.uad.ac.id/index.php/saga/article/viewFile/124/370

Astra, I. M., Nasbey, H., \& Nugraha, A. (2015). Development of an Android Application in the Form of a Simulation Lab as Learning Media for Senior High School Students. 11(5), 1081-1088. https://doi.org/10.12973/eurasia.2015.1376a

Diah, I., \& Nita, S. (2018). Media Pembelajaran Berbasis Multimedia Interaktif untuk Meningkatkan Pemahaman Konsep Mahasiswa. 1(2), 68-75. https://doi.org/http:// doi.org/10.25273/doubleclick.v1i2.1540

Fadli, F. (2014). Model pembelajaran jejaring sosial pada pelajaran matematika. Perspektif Ilmu Pendidikan, 28(2), 90. https:/ / doi.org/10.21009/pip.282.2

Faslah, R. (2016). Model of the use of information technology in improving the ability of student (experimental study tools search engine in sma negeri 1 parung bogor). Econosains Jurnal Online Ekonomi dan Pendidikan, 14(1), 70-87. https://doi.org/10.21009/econosains.0141.06

Febrialismanto, \& Hukmi. (2018). Perbedaan Kompetensi Profesional Guru PG PAUD Kabupaten Siak Dengan Kabupaten Kampar Provinsi Riau. 7(1), 61-68.

Febrialismanto, \& Nur, H. (2019). Kemampuan Guru Menggunakan TIK Untuk Pengembangan di. KINDERGARDEN: Journal of Islamic Early Childhood Education, 2(2), 101-111. https:// doi.org/http://dx.doi.org/10.24014/kjiece.v2i2.8296

Febrialismanto, \& Nur, H. (2020). Hubungan Aktivitas Penggunaan Teknologi dengan Memilih TIK Untuk Pengembangan Anak Usia Dini. PAUD Lectura, 3(2), 28-39. https://doi.org/https:// doi.org/10.31849/paud-lectura.v3i02.3886

Hendikawati, P., Zahid, M. Z., \& Arifudin, R. (2019). Android-Based Computer Assisted Instruction Development as a Learning Resource for Supporting Self-Regulated Learning. International Journal of Instruction, 12(3), 389-404. https://doi.org/https:// doi.org/10.29333/iji.2019.12324a

Hendriawan, M. A., \& Muhammad, G. M. (2018). Pengembangan Jimath Sebagai Multimedia Pembelajaran Matematika Berbasis Android Untuk Siswa Sekolah Menengah Atas. Jurnal Matematika dan Pembelajaran, 6(1), 274-288. https://doi.org/https:// doi.org/10.24252/mapan.2018v6n1a12

Husain, C. (2014). Pemanfaatan Teknologi Informasi dan Komunikasi dalam Pembelajaran di SMA Muhammadiyah Tarakan. Jurnal Kebijakan dan Pengembangan Pendidikan, 2(2004), 184-192. https:// doi.org/https:/ / doi.org/10.22219/jkpp.v2i2.1917

Indonesia, P. M. P. dan K. R. (2014). Kurikulum 2013 Pendidikan Anak Usia Dini.

Irnin Agustina Dwi Astuti, Dasno, R. A. S. (2018). Pengembangan Media Pembelajaran 
Berbasis Android pada Materi Kelarutan. Jurnal Pengabdian Kepada Masyarakat, 24(2), 695-701. https://doi.org/http://dx.doi.org/10.21831/jipi.v2i1.10289

Jelita, J. (Tarbiyah P. P. M. S. Z. C. K. L. (2013). Penggunaan Fasilitas WiFi dan Pengaruhnya terhadap Indeks Prestasi Mahasiswa Prodi Pendidikan Matematika (Studi pada Mahasiswa Prodi Pendidikan Matematika STAIN Zawiyah Cot Kala Langsa). Logaritma, $1(1)$,

110-120.

https:/ /doi.org/https://doi.org/10.24952/logaritma.v1i01.197

Kamhar, M. Y., \& Lestari, E. (2019). Pemanfaat Sosial Media Youtube Sebagai Media Pembelajaran $\begin{array}{lllll}\text { Bahasa Indonesia DI Perguruan } & \text { Tinggi. }\end{array}$ https:// doi.org/http://dx.doi.org/10.33366/ilg.v1i2.1356

Komariah, S., Suhendri, H., \& Hakim, A. R. (2018). Pengembangan Media Pembelajaran Matematika Siswa Smp Berbasis Android. Jurnal Kajian Pendidikan Matematika, 4(1), 4352. https://doi.org/http:/ / dx.doi.org/10.30998/jkpm.v4i1.2805

Martono Kurniawan, T., \& Nurhayati Oky, D. (2014). Implementation of Android-Based Mobile Learning Application as a Flexible Learning Media. International Journal of Computer Science Issues, 11(3), 168-174.

Meolbatak, E. M., \& Bria, Y. P. (2016). Penerapan Model Multimedia Sebagai Media Pembelajaran Alternatif Untuk Meningkatkan Self Motivated Learning Dan Self Regulated Learning. Media Teknika Jurnal Teknologi, 11(2), 83-90. https:// doi.org/http:/ / dx.doi.org/10.24071/mt.v11i2.519

Munirah. (2018). Penggunaan aplikasi whatsapp pada pembelajaran menulis paragraf narasi bahasa indonesia. Kemendikbud. http://repositori.kemdikbud.go.id/

Muyaroah, S., \& Fajartia, M. (2017). Pengembangan Media Pembelajaran Berbasis Android dengan menggunakan Aplikasi Adobe Flash CS 6 pada Mata Pelajaran Biologi Abstrak. Innovative Journal of Curriculum and Educational Technology, 6(2301), 79-83.

Ningrum, N. K., Toenlioe, A. J., \& Abidin, Z. (2019). Analisis Pemanfaatan Search Engine Dalam Meningkatkan Self-Regulated Learning. Jurnal Kajian Teknologi Pendidikan, 2(2), 149-157. https://doi.org/http:/ / dx.doi.org/10.17977/um038v2i22019p149

Nisa', L. (2020). Pemanfaatan Teknologi Dalam Pendidikan Anak Usia Dini. ThufuLA: Jurnal $\begin{array}{llll}\text { Inovasi Pendidikan Guru Raudhatul Athfal, } 001 . & \end{array}$ https:// doi.org/10.21043/thufula.v8i1.6283

Nopriyanti, N., \& Sudira, P. (2015). Pengembangan multimedia pembelajaran interaktif kompetensi dasar pemasangan sistem penerangan dan wiring kelistrikan di SMK. Jurnal Pendidikan Vokasi, 5(2), 222-235. https://doi.org/10.21831/jpv.v5i2.6416

Nurhayati, A. S. (2016). Prosiding temu ilmiah nasional guru (ting) viii. VIII, 621-631.

Nurhayati, N., Suciati, U., \& Heriyanti, M. E. N. (2014). Perilaku Pencarian Informasi Mahasiswa Pascasarjana Universitas Gadjah Mada di Era Search Engine. JURNAL IPTEKKOM: Jurnal Ilmu Pengetahuan $\mathcal{E}$ Teknologi Informasi, 16(1), 29. https:// doi.org/10.33164/iptekkom.16.1.2014.29-40

Priantama, R. (2017). Efektivitas wi-fi dalam menunjang proses pendidikan bagi lembaga perguruan tinggi (studi kasus terhadap mahasiswa pengguna di lingkungan universitas kuningan). Jurnal Cloud Information, 1(1), 22-28.

Priyanto, D. (2009). Pengembangan Multimedia Pembelajaran Berbasis Komputer. 14(1), 1-13.

Purbosari, H. B. (2019). Aplikasi Android Sebagai Pembantu Tugas Guru Di Kelas. Seminar Nasional Pendidikan (SENDIKA), 18.

Ramdan, M., Hamidah, I., \& Purnawan, P. (2015). Penerapan pola pembelajaran berbasis multimedia terhadap peningkatan hasil belajar siswa smk pada materi katup pneumatik. 2(1), 83-90. https:/ / doi.org/: https://doi.org/10.17509/jmee.v2i1.1157

Rusi Restiyani, Nengsi Juanengsih, Y. H. (2013). Profil Pemanfaattan Teknologi Informasi dan Komunikasi (TIK) Sebagai Media dan Sumber Pembelajaran Oleh Guru Biologi. Journal of Chemical Information and Modeling, 53(9), 1689-1699. https:/ / doi.org/10.1017/CBO9781107415324.004 
Saefi, M., Lukiati, B., \& Suarsini, E. (2017). Developing Android-Based Mobile Learning On Cell Structure And Functions Lesson Subject Topic To Optimize Grade XI Students' Cognitive Comprehension. Jurnal Pendidikan Sains, 5(2), 57-63.

Sasmito, M. (2015). Pemanfaatan Media Sosial Facebook Untuk Media Pembelajaran Bahasa Indonesia Mayasari. Metafora, 1(2), 184-198.

Setiadi, A. (2018). Pengembangan Aplikasi Android Untuk Pembelajaran Pneumatik. Jurnal Pendidikan Vokasional Teknik Elektronika, I(1), 1-5.

Setiyani, R. (2010). Pemanfaatan Internet Sebagai Sumber Belajar. Dinamika Pendidikan, 5(2), 117-133. https:// doi.org/10.15294/dp.v5i2.4921

Shilpa, S., \& Sunita, M. (2013). Impact of multimedia in early childhood education. Journal of Management and Science, 1(3), 430-435. https:// doi.org/10.26524/jms.2013.47

Sri Mulyani, E. W. (2018). Dampak Pemanfaatan Aplikasi Android Dalam Pembelajaran Bangun Ruang. Kwangsan: Jurnal Teknologi Pendidikan, 6(2), 122-136. https://doi.org/10.31800/jtp.kw.v6n2.p122--136

Studi, P., Informasi, S., Komputer, F. I., \& Darma, U. B. (2009). Pengaruh Penggunaan Search Engine , E-Mail Dan Mailing List Terhadap Kualitas Informasi. Jurnal Sistem Informasi (JSI), 1(3), 113-127.

Suharmanto, A. (Pendidikan kewarganegaraan dan hukum U., \& Sunarso, S. (Pendidikan kewarganegaraan dan hukum U. (2017). Pemanfaatan Internet ... ( Anang Suharmanto) | 24. Jurnal Pendidikan Kewarganegaraan dan Hukum, 1(5), 24-41.

Sum, T. A. (2019). Kompetensi Guru Paud Dalam Pembelajaran Di Paud Di Kecamatan Langke Rembong Kabupaten Manggarai. Jurnal Lonto Leok Pendidikan Anak Usia Dini, 2(1), 68 75.

Tafonao, T. (2018). Peranan media pembelajaran dalam meningkatkan minat belajar mahasiswa. Jurnal Komunikasi Pendidikan, 103. https://doi.org/10.32585/jkp.v2i2.113

Zakiya, \& Nurhafizah. (2019). Pengembangan Keprofesian Berkelanjutan dalam Meningkatkan Profesionalisme Guru Pendidikan Anak Usia Dini. Jurnal Obsesi, 3(2), 356-365. https:// doi.org/10.31004/obsesi.v3i2.196

Zulhelmi, Z. ( U. S. K. B. A., Adlim, A. (Universitas S. K. B. A., \& Mahidin, M. (Universitas S. K. B. A. (2017). Pengaruh media pembelajaran interaktif terhadap peningkatkan keterampilan berpikir kritis siswa. Jurnal Pendidikan Sains Indonesia (Indonesian Journal of Science Education), 5(1), 72-80. 